\title{
Visual reactions in a case of long-lasting cortical blindness
}

\author{
J. W. G. TER BRAAK, V. W. D. SCHENK, AND A. G. M. VAN VLIET \\ From the Dijkzigt Hospital, Medical Faculty, Rotterdam, Holland
}

SUMMARY A case is described of long-lasting cortical blindness in a 71 year old man showing no other visual reactions than pupillary narrowing to light and (only after some months) optokinetic nystagmus of the 'passive' type. Necropsy demonstrated total bilateral destruction of the striate area of the cortex caused by bilateral softening in the territory of the posterior cerebral artery, and nearly total loss of ganglion cells in both lateral geniculate bodies.

Complete blindness due to a cerebral lesion persisting for months or years is a relatively rare condition.

More frequently, a temporary cortical blindness is observed in traumatic or vascular diseases, lasting for several days, after which some visual reactions reappear; not uncommonly a homonymous hemianopia remains. Other cases, where the picture is less clear, have been labelled 'bilateral hemianopia' and have been distinguished from total blindness by the sparing of the central part of the visual field. Further still more intricate cases have been referred to as 'visual agnosia'.

In the classical view there is an essential difference between 'cortical blindness' and 'bilateral hemianopia' on the one hand, and 'visual agnosia' on the other. This difference can be traced back to the work of Munk, who distinguished Seelenblindheit from Rindenblindheit, the former consisting in a loss of visual Vorstellungen ('memory images') and the latter in a loss of visual Wahrnehmungen ('perceptions').

The validity of Munk's assumptions has already been disputed by his contemporaries and at present his distinction is of only historical value, although it is tacitly still present in the distinction between 'cortical blindness' and 'visual agnosia'.

According to this distinction, there ought to be an essential difference between partial (recovering) cortical blindness and visual agnosia. The disturbance in the former could be described in terms of visual field defects, whereas the visual agnosia could be described in terms of impairment of higher visual performance. The striking behavioural difference, however, in natients with field defects caused by optic tract or chiasmal lesions proves that in $\underset{\perp}{\dot{\omega}}$ partial cortical blindness the higher visual perform ances are also impaired.

In cases of persistent total cortical blindness the differentiation from agnosia would be simplea 을 because in accordance with the definition there a no visual reactions at all. Here it is not the disting tion from visual agnosia which causes difficultie but the distinction from 'blindness' of peripher $\vec{f}$ origin. The distinction is based on the following criteria:

1. In a considerable number of cases there is 'denial of blindness' (Anton's symptom) in cortical blindness.

2. The EEG in cases of cortical blindness shows absence of $a$-rhythm and no responses on eye opening and closure.

3. The pupillary reactions to light are still present in cortical blindness.

The question may be raised, whether the presence of pupillary reactions to light is not in contradiction with the definition of 'blindness' as a complete? absence of visual reactions. However, it becomes clear that the term 'visual reactions' implies 'visual reactions depending on conscious vision'.

'Conscious vision' is taken for granted when a

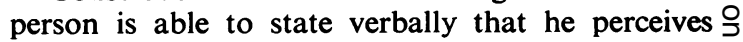
something actually present in the outer world. When $\rightarrow$ the person is not able to state verbally that he perceives something-for example, because he is N aphasic - and reacts to optic stimuli in a way which we (rather arbitrarily) consider equivalent to a $N$ verbal statement, we also admit that he is 'seeing'. N

The optokinetic nystagmus $(\mathrm{OKN})$, the slow? 
component of which is generally considered as a 'pursuit movement', would thus be a proof of 'conscious vision'. As a matter of fact in the differential diagnosis of 'cortical' and 'hysterical' blindness (in both of which cases the pupils react to light) the examination for the presence of OKN is generally recommended as a crucial test. There is a prevalent conviction that $\mathrm{OKN}$ is absent in total cortical blindness. The few authors who have taken the trouble to examine this (Magitot and Hartman, 1927; Velzeboer, 1952; Morax, 1960; Brindley, Gautier-Smith, and Lewin, 1969) are unanimous that $\mathrm{OKN}$ is absent in total cortical blindness.

Velzeboer repeatedly examined a patient inside a striped rotating cylinder and found OKN only when the total blindness was over and a certain degree of vision had returned. Because of the general belief that 'vision' depends on the integrity of the visual cortex, the return of OKN in this patient is ascribed to the recovery of the function of this area. The possibility of the recovery of reactions of the OKN type without return of 'vision' has not been considered by the majority of authors. Moreover, cases of cortical blindness lasting for many months are rare. Brindley et al. (1969) examined repeatedly a patient with total cortical blindness lasting more than $3 \frac{1}{2}$ years but could not elicit OKN.

In the lower animals (birds, reptiles) ablation of the forebrain does not produce a state which we would call 'blindness', so that 'vision' in these animals must be achieved by the relatively more powerful subcortical structures. Consequently, one is not astonished to find OKN intact, for instance, in decorticate pigeons (Visser, 1932).

In mammals (rabbit, cat, dog, monkey) the state produced by ablation of the cerebral hemispheres or of the visual cortex is much more similar to 'blindness' (although by special behavioural tests some visual discriminatory faculties can be demonstrated) and it is still possible to elicit OKN in these animals, provided that a large part of the contrasts of the outer world is moving in the same direction. This evidence led one of us (ter Braak, 1936) to make a distinction between two types of OKN:

1. 'Passive' OKN produced by the movement of the majority of contrasts in the visual field, still present after ablation of the visual cortex and even after total decortication.

2. 'Active' OKN depending on the movement of separate 'interesting' objects drawing the attention, for which 'vision' as well as intactness of the visual cortex seems a necessary condition.

The preservation of OKN in monkeys after striatectomy, however, is still disputed. Pasik, Pasik, and Krieger (1959) found OKN to be absent perma- nently after bilateral striatectomy in some animals. In others $\mathrm{OKN}$ returned (in a very abortive form) only when a 'certain degree of vision' was present (apart from the usual blinking and pupillary reactions). The authors seem to attribute this rudimentary form of OKN to some remaining parts of the visual cortex (or to some other cortical areas?).

On the other hand, Ter Braak and van Vliet (1963) maintained that in a monkey after complete striatectomy (with total disappearance of ganglion cells in the lateral geniculate body) OKN in a form not differing essentially from that in the intact monkey could be elicited. They concluded that in the monkey also the 'passive' OKN is a subcortical reflex.

In human subjects with cortical blindness previously examined by us, it was not possible to elicit OKN under the conditions favourable to 'passive' OKN. However, the examination was usually performed only a short time after the development of the blindness, because the patient was then discharged soon afterwards; in other cases the OKN returned, but together with a certain degree of 'vision', so that the term 'cortical blindness' could no longer be applied.

The patient described below offered the opportunity to repeat the examination over a period of seven months after the development of the blindness, which remained complete.

\section{CASE REPORT}

A 71 year old farmer, practically blind in one eye due to an accident in 1957 (perforation of the left cornea by an iron splinter, leaving light perception only and $9 / 10$ visual acuity in the other eye) complained for about half a year of impaired vision. Sometimes he missed the plank over which he used to push his wheelbarrow. The family doctor found a blood pressure of $210 / 120 \mathrm{~mm} \mathrm{Hg}$ and prescribed reserpine. On 21 April 1965 he was seen by an ophthalmologist who found a considerable field defect which on repeated examination (6 May) proved to be a left-side - that is, nasal-hemianopia of the right eye. During August 1965 there was a short period of mental confusion, which recurred in the beginning of September. About this time the patient complained of headache in the region of the left eye and maintained that he could see hardly anything at all. Soon thereafter he became apathetic and would not leave his chair. He grasped at things not really present ('cats and dogs') and was very frightened by unusual sounds. In this condition he was admitted to the Neurological Clinic on 7 October.

Examination immediately on admission revealed a disorientated, visually hallucinating man (he reported seeing dogs and cats). He was afraid to walk, although in fact he was able to do so and gave the impression of being totally blind. In the first period he did not complain of blindness, but after a few weeks, when he became more quiet he admitted that he could not see anything at all.

His blood pressure was $170 / 100 \mathrm{~mm} \mathrm{Hg}$. Biochemical 
tests revealed an impaired absorption of vitamin $\mathbf{B}_{12}$. Blood tests were normal.

The left eye showed an opacity of the cornea so that the pupil was not visible. The appearance of the media of the right eye was normal. Ophthalmoscopy revealed an unusually large excavation of the papilla. Pupillary reaction to light was quite normal. There was no light perception: sometimes the patient claimed that he saw light when it was dark and vice versa. The blinking reaction to light and to threatening movements was entirely absent. There was no spontaneous nystagmus. Eye movements could be executed on command, but there were no fixation movements. Optokinetic nystagmus, even on examination in the striped cylinder, was absent.

There were no signs of hemiplegia; tendon reflexes were symmetrical, and plantar reflexes normal. Walking was unimpaired, although the patient was very cautious because of his blindness.

During the observation period, the patient improved in that the confusion, restlessness, and visual hallucinations disappeared, although he remained disorientated. He continued to behave like a totally blind man and admitted that he could not see anything. But when he was asked to give his hand, the patient continuously sought for the hand of the examiner without saying that he could not see it.

During the examination of the psychosensory functions, the patient was conscious, but mentally slow. His attention could easily be roused, but he could not concentrate upon the examination for longer than a quarter of an hour, as he became rapidly tired. He was disorientated in space and time. His memory for the remote past was good, for the recent past insufficient. At a rough preliminary examination his intellectual performances appeared to be at a low normal level.

His ability to revisualize was good. He gave an exact description of the colours of flowers and rightly corrected the error in false colour-junctions like red canaries, blue roses, and so on. Another example of his ability to revisualize was his description of the town hall of his home town: 'old-fashioned, such an odd façade, a triangular front; there is a notice-board in front where names of people can be posted up'. Another was his description of a clock: (Where is the figure 12?) 'In the middle at the top'. (And where the figure 9?) 'Then you must go down one side'. (Which side?) 'Right side'. (Are you sure?) 'Now you confuse me'. (What figure is on the opposite side of the 9?) 'The figure 5, no, the figure 3'. (The patient showed obvious signs of tiredness here.)

The EEG on 18 October showed an unresponsive 7-6 $\mathrm{Hz}$ rhythm in the parieto-occipital region and in the central region, as well as unresponsive rhythm of $10-9 \mathrm{~Hz}$. Moreover, there were diffuse bilateral synchronous waves of 5-4 and 3-1 Hz of $100 \mathrm{~V}$.

The electronystagmogram (ENG) on 12 December revealed a slight nystagmus to the left during eye closure, but optokinetic stimulation in the striped cylinder failed to produce $\mathrm{OKN}$.

The ENG of 6 January 1966 showed no spontaneous nystagmus with the eyes closed or opened. For the first time, an OKN to the left could be provoked during rotation of the cylinder to the right (angular velocity $8 \frac{1}{2}^{\circ} \mathrm{sec}^{-1}$ ) followed by a short after-nystagmus in the same direc- $\bar{Z}$ tion after cessation of the stimulus (Fig. 1). During the stimulation which produced nystagmus, the patient was asked several times whether he saw any movement, but? he denied this.

On 25 May 1966 the patient was discharged to a nurs- $\square$ ing home. The neurological condition, according to the report of the home physician remained essentially the $\stackrel{5}{工}$ same. He died on 6 August 1968.

PATHOLOGY Necropsy was performed at the Dijkzigt Hospital with the following results. There was arterio- $\frac{\text { ? }}{9}$ sclerosis which was generalized and involved the brain vessels, with small old softenings in the pons, cerebellum, 듬 pulvinar, and right frontal lobe. Both occipital lobes $\overline{\bar{\sigma}}$ contained large cysts, due to old softenings, situated $\overrightarrow{\widetilde{D}}$ predominantly ventrally of the calcarine fissure, passing $\propto$ to the temporal gyri and extending to the ependyma of $\approx$ the lateral ventricles (Figs. 2 and 3). The external sagittal $\vec{\circ}$ stratum was strikingly atrophied on both sides. Some fragments of calcarine cortex could be identified only in $\vec{\omega}$ the poles of the occipital lobes, but these contained hardly. any fibres. Both lateral geniculate bodies had lost all architecture; practically all ganglion cells had disappeared (Fig. 4). There were also severe lesions of the $\omega$ hippocampus and adjacent structures which will be discussed elsewhere.

SUMMARY OF HISTORY A 71 year old man (already blinf in the left eye) first developed a nasal hemianopia of the right eye and some months later a total blindness with mental confusion and, initially, visual hallucinationg After the period of confusion was over, the patieg admitted his total blindness. In the beginning the pupis. $\vec{\bullet}$ lary reactions to light were the only visual reactions, but after about four months an optokinetic nystagmus to the left could be elicited by slow movements of a large field of optical contrasts, during which he denied seeing any movement. The necropsy revealed practically total destruction of both striate areas and degeneration of both lateral geniculate bodies.

\section{DISCUSSION}

The pathological findings (destruction of both striate areas and retrograde degeneration of lateral geniculate bodies), probably caused by thrombosis of both posterior cerebral arteries in two stages, give a satisfying explanation for the clinical picture which could be classified as a 'bilateral hemianopia'. This term is usually applied only when there is some sparing of the central part of the visual field, since in a unilateral hemianopia the macular region has also been spared. The most common explanation for this phenomenon is that the extent of the cortical representation of the macula is large so that it may easily escape the process of softening. However, as there are also cases of hemianopia without sparing of the macula which may occur bilaterally, it is quite possible that 'bilateral hemianopia' can produce a total visual field defect as in our patient. 
a
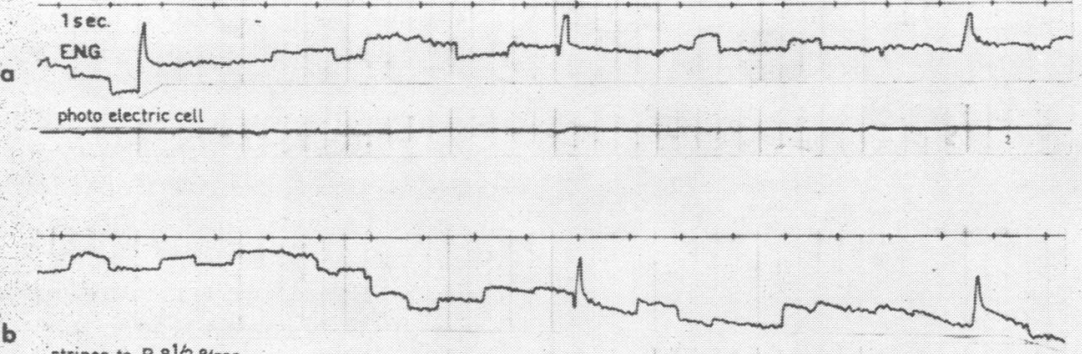

stripes to $R$ 8 $1 / 2 \% / \mathrm{sec}$

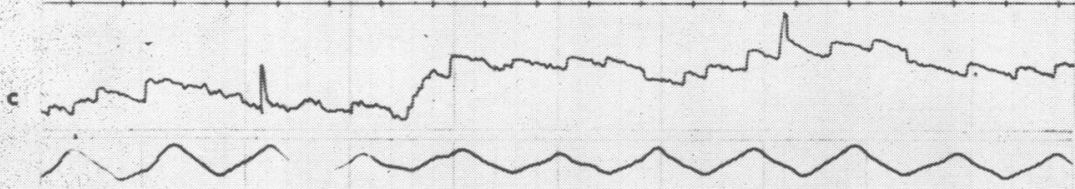

d
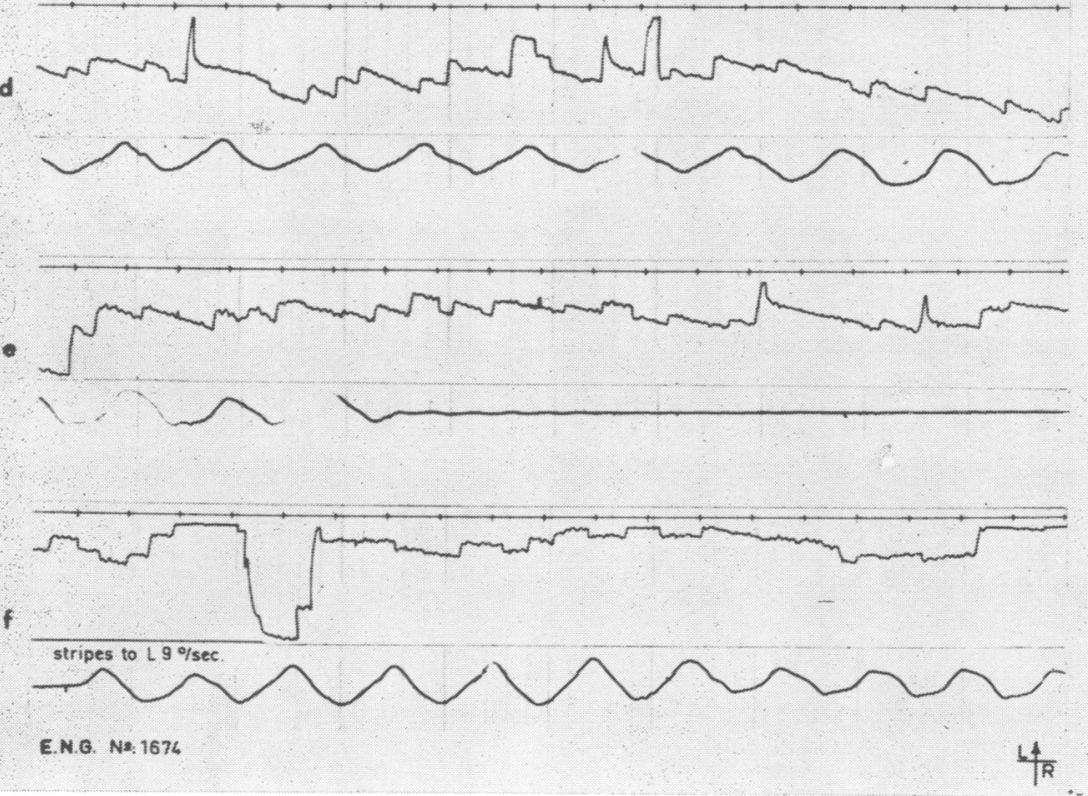

FIG. 1. Upper trace: electronystagmogram (DC recording) (eye movement to the left: upward deflection). Lower trace: photocell record indicating frequency of rotating cylinder stripes. a. Striped cylinder at rest: only random eye movements. b-e. Stripes moving to right: nystagmus to the right appearing gradually and disappearing gradually after cessation of the stimulation. f. Stripes moving to left: only random eye movements. 


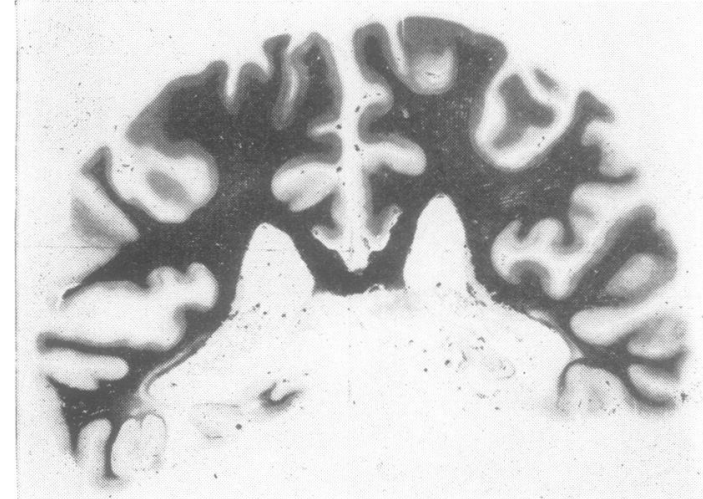

FIG. 2. Frontal section through splenium corporis callosi (Klüver-Barrera). At both sides extensive necrosis of hippocampal and occipito-temporal gyri and degeneration of external sagittal stratum.

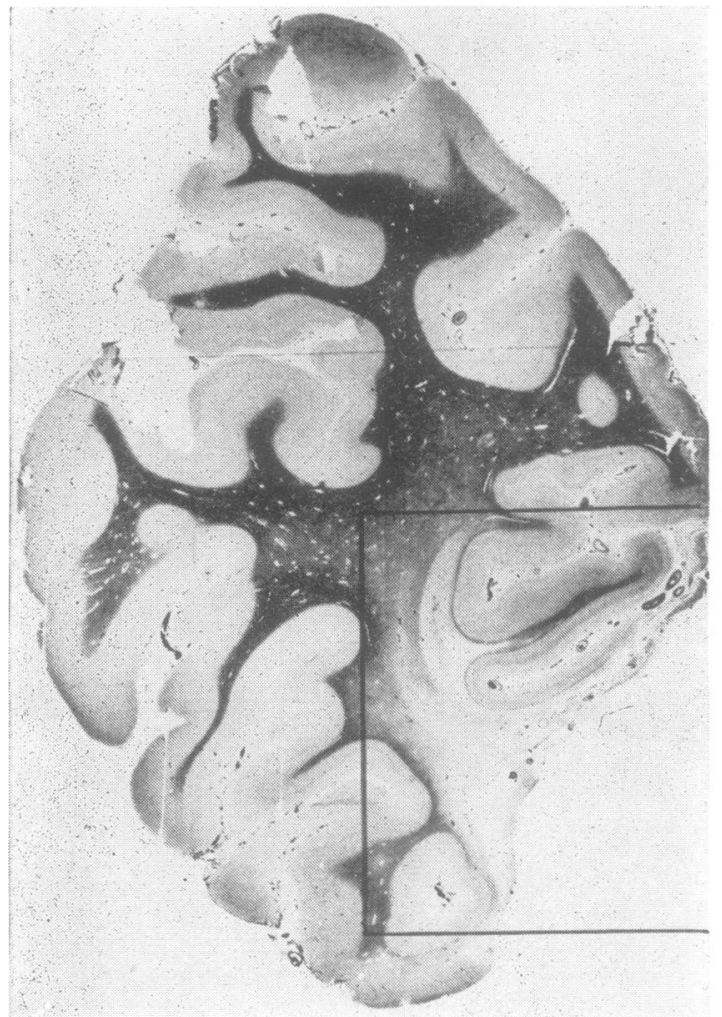

As the only sign of return of visual reactions in ourz patient consisted in the positive 'passive' OKN, he belongs to the relatively rare group remainingo 'blind' for more than half a year (probably for the rest of his life).

It is the return of OKN (albeit in a rudimentaryos form) which is the main motive for publication of this case. In our patient the return of OKN was not as in some other cases, for instance that of Velzeboer (1952) and case 2 of Brindley et al. (1969)-accompanied by signs of recovery of vision. We should like to stress the importance of the fact that the patient, when displaying an OKN, denied seeing any move-음 ment. It is therefore very improbable that the slow phase of OKN consisted in a 'pursuit movement' of distinct visual objects. Thus the OKN shows the characteristics of the 'passive' OKN more convinc-

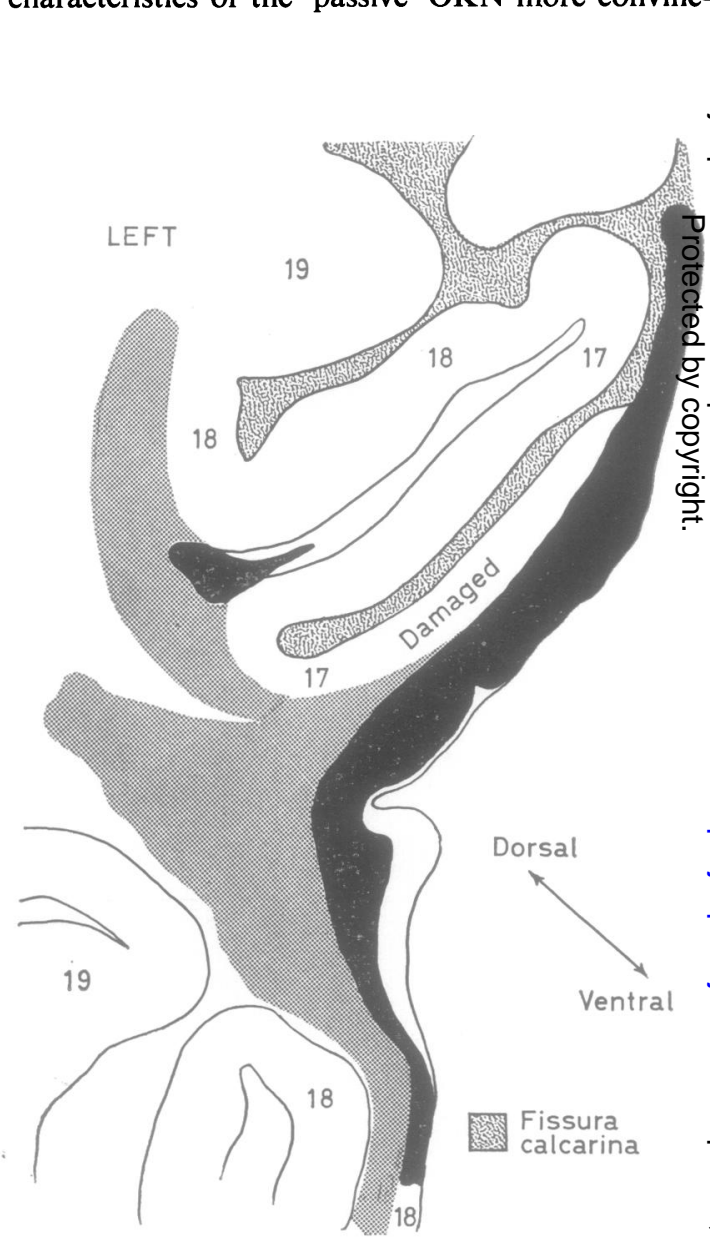

FIG. 3a

FIG. 3. Frontal sections of both occipital lobes (Klüver-Barrera) with drawings of outlined parts. (a) left side; (b) right $\stackrel{\mathrm{N}}{\mathrm{N}}$ side. Extensive damage of external sagittal strata. Several completely necrotic zones in cortex. In drawings: black = $\omega$ cystic degeneration; grey = atrophy of subcortical white matter. Numbers indicate cortical areas according to Brodmann 0 
ingly than is possible in normal subjects, in whom it is nearly impossible to state whether they 'look' at the moving objects or not, even if they are asked not to pay attention to them.

The situation in the patient is very analogous to that in striatectomized animals, so that we feel justified in supposing that the OKN in this case was 'subcortical'. The geniculocalcarine pathway, in view of its nearly total destruction, could hardly be involved.

Whether this case must be considered as a real exception among other cases of cerebral blindness is a question which cannot be answered affirmatively because an adequate examination of 'passive' OKN at various intervals after the onset of the blindness has seldom been performed. Moreover, as appears from the nystagmogram of Fig. 1, the speed of the slow phase increases slowly after the beginning of the stimulation, much more slowly than under normal conditions, and there is a pronounced 'afternystagmus', which in a normal person is only present when the eyes are closed or the room is darkened. Perhaps the parameters of stimulation are important. We performed the examination within a drum with 22 black stripes at a relatively low velocity $\left(8.5^{\circ} / \mathrm{sec}\right)$, which provides a strong optokinetic stimulus.

In the papers of Velzeboer (1952) and Brindley et al. (1969) the angular velocity of the moving contrasts is not mentioned. ${ }^{1}$

The absence of OKN for several months in our case, may be ascribed to 'diaschisis' exerted on the subcortical nystagmus centres, but also to temporary lesions of the midbrain caused by ischaemia in the territory of the posterior cerebral artery. The pathological findings, however, give little support to the latter supposition. The presence of spontaneous nystagmus in the initial period, on the other hand, could point in this direction.

From the studies in the monkey we also know that the recovery of the 'passive' OKN does not take place until a certain time has elapsed. For the

'Professor Brindley kindly informs us that he re-examined his case 2 on 25 May 1970 at a drum speed of $6^{\circ} / \mathrm{sec}$. OKN was completely absent.

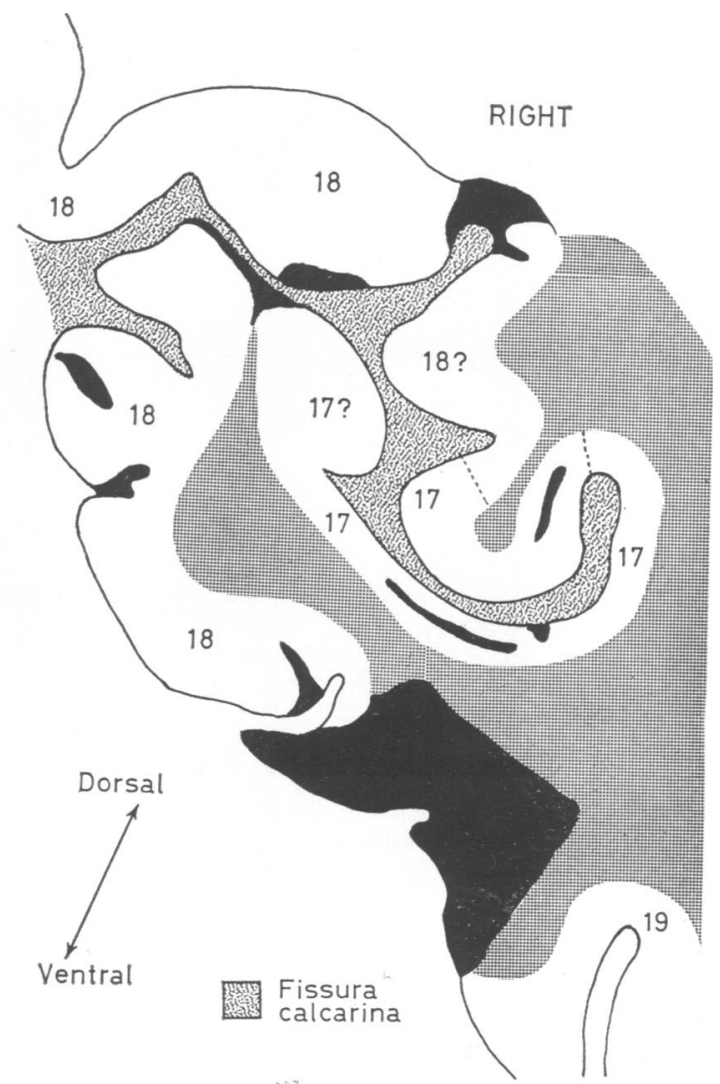

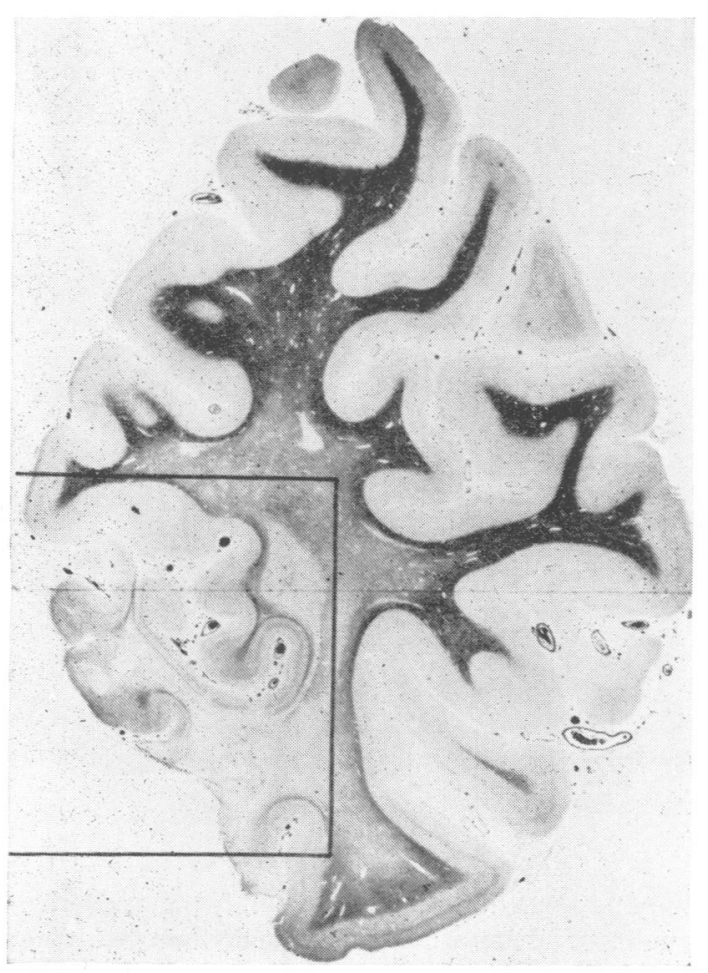



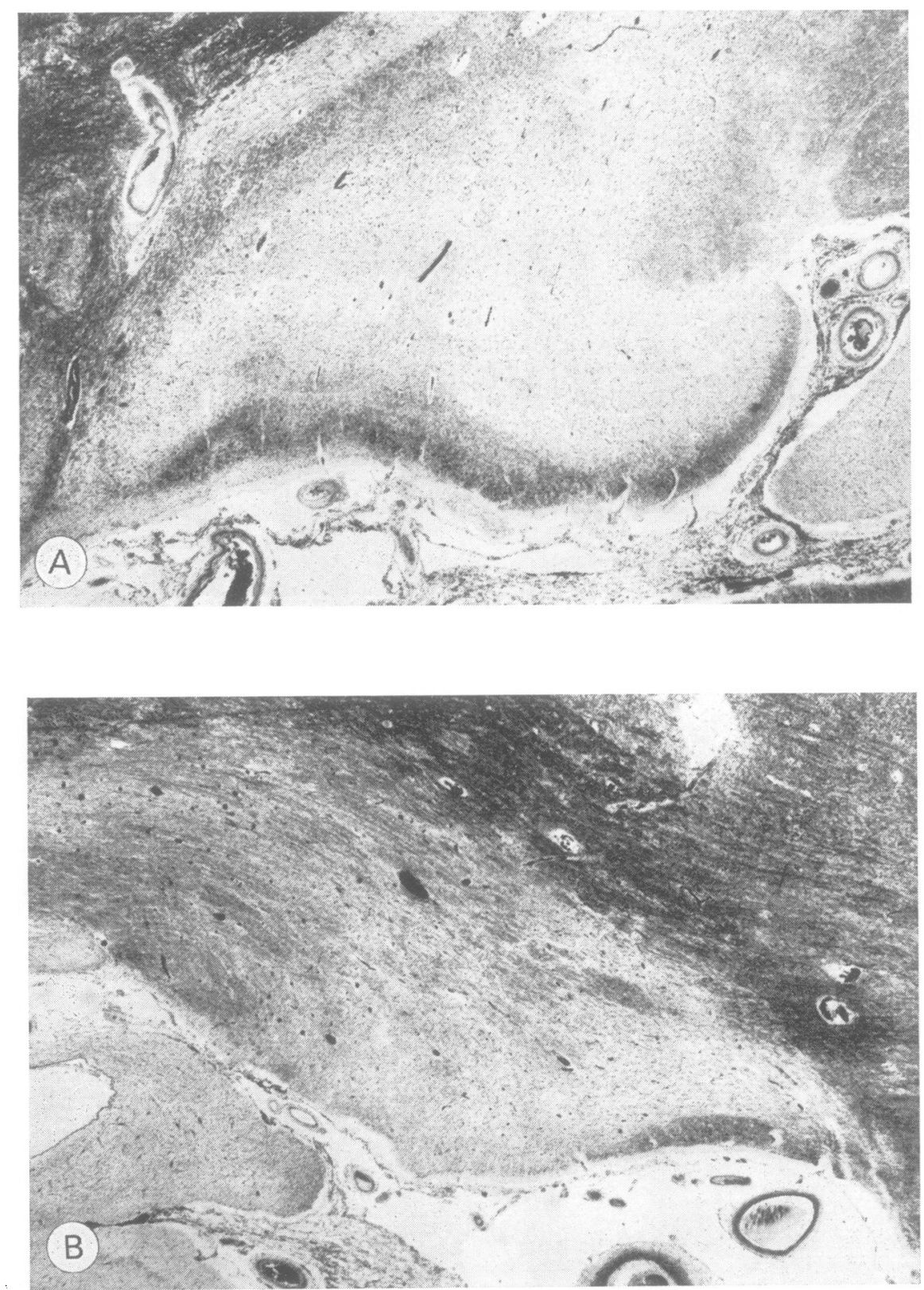

"pig. 4. Frontal sections of both lateral geniculate bodies. Complete loss of architecture and almost complete loss of nerve cells. Myelin stained fibres at ventral side only (optic tract fibres). (Klüver-Barrera.) A: right; B: left side.

future it is therefore desirable to examine patients with 'cortical blindness' at several intervals over many months after the onset of blindness.

Are we justified in speaking of 'total cortical blindness' although optical 'following movements' could be demonstrated? The answer, of course depends on the definition of 'blindness'. The presences of pupillary reactions to light has never been con? 
sidered incompatible with 'blindness', but eye movements, pursuing optical contrasts, would present more difficulties. It is not relevant here that the following movement is not 'conscious' in the sense of 'voluntary', for following movements during 'normal' OKN-for example, in looking from the window of the railway carriage-are no more 'voluntary' or 'conscious'.

If we adhere to the definition mentioned above and call a patient 'blind' when he is not able to state verbally (or by some equivalent of speech) that he perceives anything actually present in the outer world, then our patient can be called 'blind', for he denied seeing any movement despite the pursuit movements of the eyes.

It is clear, however, that our definition of 'blindness' is rather arbitrary. It may be asked, whether the term 'blindness', which is useful to describe disturbances of the eye and of the peripheral optic pathways, is also appropriate for the description of central disorders, in the same way as 'paralysis' is more suited to describe lower, rather than upper, motor neurone disorders.

\section{REFERENCES}

Brindley, G. S., Gautier-Smith, P. C., and Lewin, W. (1969). Cortical blindness and the functions of the non-geniculate fibres of the optic tracts. J. Neurol. Neurosurg. Psychiat., 32, 259-264.

ter Braak, J. W. G. (1936). Untersuchungen über optokinetischen Nystagmus. Arch. Néerlandaises de Physiol., 21, 309-376.

ter Braak, J. W. G., and van Vliet, A. G. M. (1963). Subcortical optokinetic nystagmus in the monkey. Psychiat. Neurol. Neurochirurg. (Amst.), 66, 277-283.

Kornhuber, H. (1966). Physiologie und Klinik des zentralvestibulären Systems (Blick- und Stützmotorik). In HalsNasen-Ohrenheilkunde: ein kurzgefasstes Handbuch. Edited by J. Berendes, R. Link, and F. Zoellner, Bd III Teil 3, p. 2233. Thieme: Stuttgart.

Magitot, A., and Hartmann, E. (1927). La cécité corticale. Rev. Oto-neuro-opthal., 5, 8.

Morax, P. V. (1960). La cécité corticale, In Les Grandes Activités du Lobe Occipital, p. 217. Edited by T. Alajouanine. Masson: Paris.

Pasik, P., Pasik, T., and Krieger, H. P. (1959). Effects of cerebral lesions upon optokinetic nystagmus in monkeys. J. Neurophysiol., 22, 297-304.

Velzeboer, C. M. J. (1952). Bilateral cortical hemianopsia and optokinetic nystagmus. Ophtalmologica (Basel), 123, 187-188.

Visser, J. (1932). Optische reacties bij duiven zonder grote hersenen. Thesis: Leiden. 